BLS 35, No 1 2009. DOI: http://dx.doi.org/10.3765/bls.v35i1.3611

(published by the Berkeley Linguistics Society and the Linguistic Society of America)

\title{
Format Tying and the Acquisition of Syntax in Toddlers' Peer Interactions
}

\author{
S. BAHAR KÖYMEN and AMY KYRATZIS \\ University of California, Santa Barbara
}

\section{0. $\quad$ Format Tying}

Goodwin (1990) defines format tying as participants' strategic use of the surface structures (such as phonological, syntactic, and semantic surface structures) of prior utterances through exact or elaborated repetitions. That is, format tying is a "publicly available apparatus for tying talk in one turn to another" (Goodwin 2006:12). There are other terms in the literature, capturing phenomena similar to format tying, such as "dialogic syntax," studied by Du Bois (2001), and "dialogic priming" studied by Bock and Loebell (1990). This study examines how young children make interactional use of format tying, and how extended sequences of turns involving format tying may serve young children as a context for learning the grammatical structures surrounding verbs.

Format tying in child language is important to study, firstly because at early ages repetitions constitute a large portion of children's conversational discourse (Goodwin 1990, Keenan 1977). Very young children who are acquiring language do not have many semantic and syntactic resources available to them to work with; thus, they rely heavily on repetitions in their conversations (Keenan 1977). Secondly, repetition is a linguistic phenomenon whose importance has been underestimated (Keenan 1977). Keenan (1977) argued that repetition was usually equated with imitation, which undervalued children's linguistic competence and what they try to accomplish with repetitions. Eventually, "strategic use" of repetitions should be highlighted and children's repetitions may be regarded as strategic moves in their conversations to achieve communicative goals, such as display of alignments, and accomplishment of one-upsmanship in their peer interactions (Corsaro and Maynard 1996, Goodwin 1990).

The most important feature of format tying is that it allows speakers to exploit syntactic and pragmatic resources within a conversation. As Goodwin (1990) highlights the communicative goals are not necessarily independent of the syntactic surface structures in the prior talk. That is, the linguistic forms and functions are highly intertwined (Slobin 1985). Below is an example of an episode of format tying among elementary school children studied by Goodwin. 


\title{
Format Tying and Syntax in Toddlers' Peer Interactions
}

\author{
(1) A: Why don't you get out of my yard., \\ B: Why don't you make me get out the yard. (Goodwin 1990:180)
}

Adding the phrase "make me" turns an already confrontational command into confrontational causative construction. Thus, format tying can be an interactional resource, especially for young children to "construct and reconstruct their social organization on an ongoing basis" (Goodwin 1990:33).

\section{Conversational Repetitions and Argument Structure}

Studies have found that, in mother-child conversations, extended rounds of repetitions facilitate the acquisition of syntax (Clancy 1996, 2009, Du Bois 2001, Küntay and Slobin 1996). For instance, Küntay and Slobin (1996) found that in mother-child conversations, Turkish mothers repeated a particular verb frame over and over varying particular arguments of the verb to maintain the child's attention. They argued that through this practice, which they termed "variation sets." Children learn particular features of the grammar of their language (for instance, in this case, Turkish-speaking children learn that word order is flexible in Turkish).

Participation and involvement in conversations through format tying and repetitions provides a rich context that facilitates learning. Du Bois (2001) lists a number of reasons why dialogic syntax provides "an ideal site for the on-going learning of all levels of linguistic structure" (see also Clancy 2009). Similarly, Miller and Ervin (1964) found that repetitions in conversations assist syntactic learning. In the present study, we examine how participation in conversations through format tying supports children's development of the argument structure of verbs. In this study, "argument structure" is defined as all the arguments that a verb takes, such as the subject, object, and recipient, as well as oblique arguments, such as expressions of manner, locatives, and temporal adverbs (Parisi and Antonucci 1974 as cited in Slobin 1979). The approach taken here is consistent with other literature (e.g. Budwig 1995, Clancy 1996, Cook-Gumperz and Kyratzis 2001, Ervin-Tripp 1993, Hopper 2001, Langacker 2001, Thompson and Hopper 2001) which has documented ways in which grammar can be viewed as a discourse-embedded phenomenon.

\section{Research Questions}

The present paper is part of a larger study, a master's thesis (Köymen 2008) which investigated whether and how toddlers were able to engage in peer conversations strategically through use of format tying in their conversations and how conversational repetitions and format tying supported aspects of the development of syntax, such as the development of the argument structure of verbs.

One important gap in the literature is that peer talk has been rather ignored in the acquisition of grammar. This is probably due to the fact that the acquisition of grammar is mostly studied through the child-directed speech of caregivers, which takes place at an early stage, when children are not believed to be systematically 


\section{S. Bahar Köymen and Amy Kyratzis}

exposed to peer interactions. However, currently, more and more toddlers attend daycare centers and spend significant amounts of time in interaction with their peers in daycare.

Out of all the instances of format tying identified in the database utilized here (see below), we selected the ones that were sustained for at least four turns, and examined how extended sequences of turns involving format tying may serve young children as a context for learning the grammatical structures surrounding verbs.

\section{A Study of Extended Sequences of Format Tying 3.1. The Database}

The data come from an ethnographic archival database which consists of 500 hours of video recordings of children's naturalistic interaction in two toddlerinfant daycare centers in Southern California. Videotaping took place twice weekly over a two-year period. The researchers focused on peer-to-peer interactions, as well as on peer-to-caregiver interactions in various contexts such as indoor or outdoor free play and snack time. The ages of the children attending these daycare centers ranged between 18-30 months. Seven target children who were in the same cohort and participated in steady friendship groups were singled out for Köymen's (2008) master's thesis study. All the videotapes in which at least two of the target children participated were watched by the researcher (S.B.K). All of the instances of format tying were pulled out. These excerpts were transcribed using the Du Bois, Cumming, Schuetze-Coburn, and Paolino (1992) transcription system (see the appendix for the transcription conventions).

\subsection{Data Reduction: Episodes of Extended Sequences of Format Tying}

Episodes of extended sequences of format tying were defined as meeting two criteria: (1) expanding an argument structure of another speaker's utterance through varying an element or adding one into the next turn. The cases of expanding previous speaker's utterances were often for the purpose of topping. (2) These expansions should persist for four or more turns so that the persistent nature of these extended sequences was clear. Four or more turns was the criterion for persisting on a theme because format tying requires at least 2 speakers, and each speaker contributes more than once before the topic is dropped. All such episodes involving at least two of the seven target children were identified and pulled out for further analysis. Structural and functional features of such episodes are discussed in greater detail elsewhere (Köymen and Kyratzis 2009).

\subsection{The Analysis of Extended Sequences of Format Tying}

Extended sequences of format tying that target children produced were analyzed line by line for: (1) what kinds of variations the children made on the format of the utterances of prior speakers; and (2) how these variations supported the use and learning of argument structure. This paper shows two examples addressing these research questions. 


\section{Examples}

In the following example, Eathan and Kimmy are on top of a slide and they compete with each other in terms of how high and how fast they go up stairs of the slide. ${ }^{1}$ In their extended sequence of format tying to one another, they practice the argument structure of "I go up," adding relevant arguments of speed, number, and manner.



In line 2, Eathan makes a challenge, "Did you -- up(Hx) to- to ..two now," possibly challenging Kimmy by asking her whether she has climbed up two steps of the slide. He elides the verb here. In line 3, Kimmy takes Eathan's question and turns it into a declarative form, ("I go [up to two]"), showing that she can meet his challenge, and adding the verb "go" to his original construction. In line 4, Eathan upgrades the challenge by increasing the number of steps Kimmy should be going up, from two to five "[Did-- did you--] up two-- up five." In lines 6-9, Kimmy ties to the statement embedded in Eathan's challenge, first claiming that she has gone up two steps ("I go up to ^two now," lines 6-7), then saying she has gone up to five steps, ("I go up.. five," line 9), thereby meeting his challenge. In line 10, Eathan recycles Kimmy's utterance, and indicates that he goes up five too, maintaining an equal footing with Kimmy. He also switches to a near-progressive

\footnotetext{
${ }^{1}$ All names are pseudonyms.
} 


\section{S. Bahar Köymen and Amy Kyratzis}

form, changing her "I go" to "I'm go." By adding the (contracted) copula verb here, he might be taking an alternative viewpoint on the event, viewing it more from the inside the event rather than taking a more distanced perspective on it, as argued by Langacker (2001). Up to now, he has been merely challenging Kimmy, now he is making his own statements. Then, in line 12, Kimmy ties to this utterance by deleting the arguments of direction and distance, and by adding the argument of the speed of going with the comparative ending "er," "I go ^faster and ^faster." By using the comparative adverb "faster and faster," Kimmy explicitly upgrades his utterance. Then, Eathan ties to this by saying, " $\mathrm{HI}$ 'm goin' faster and faster" in line 13. He recycled the same utterance as Kimmy, but he completes the progressive aspect that he initiated in line 10 by adding "-ing" to "go," saying "\#I'm goin' faster and faster." Then in line 14, Kimmy repeats his utterance, ("I going.. ^faster and ^faster."), using the progressive form ("I going") as he had done, although she elides the contracted copula. In lines 18-19, she intensifies the statement by repeating the comparative adverb an additional time, "and faster."

Thus, across lines 1-19, a quite complex argument structure is produced dialogically across turns with arguments of manner, speed, distance, and time. The children even vary question and declarative forms of the same utterance (repeating "Did you [go] up" and "I go up") across different turns. They also vary the viewpoint that is taken for the same event (simple present to progressive).

The example in (2) showed children adding adverbial arguments of manner, speed, distance, and time to the constructions of prior speakers, as well as varying viewpoint and aspect. The next example shows children adding complexity in terms of contracted copula verbs and causal clauses. The excerpt begins with a pretend play that is triggered by singing the birthday song, through which one boy, Devon, claims himself as the birthday boy and a girl, Sammy, goes along with it.

$$
\text { [Devon }(2 ; 6 ; 16) \text {, Sammy }(2 ; 9 ; 8)]
$$

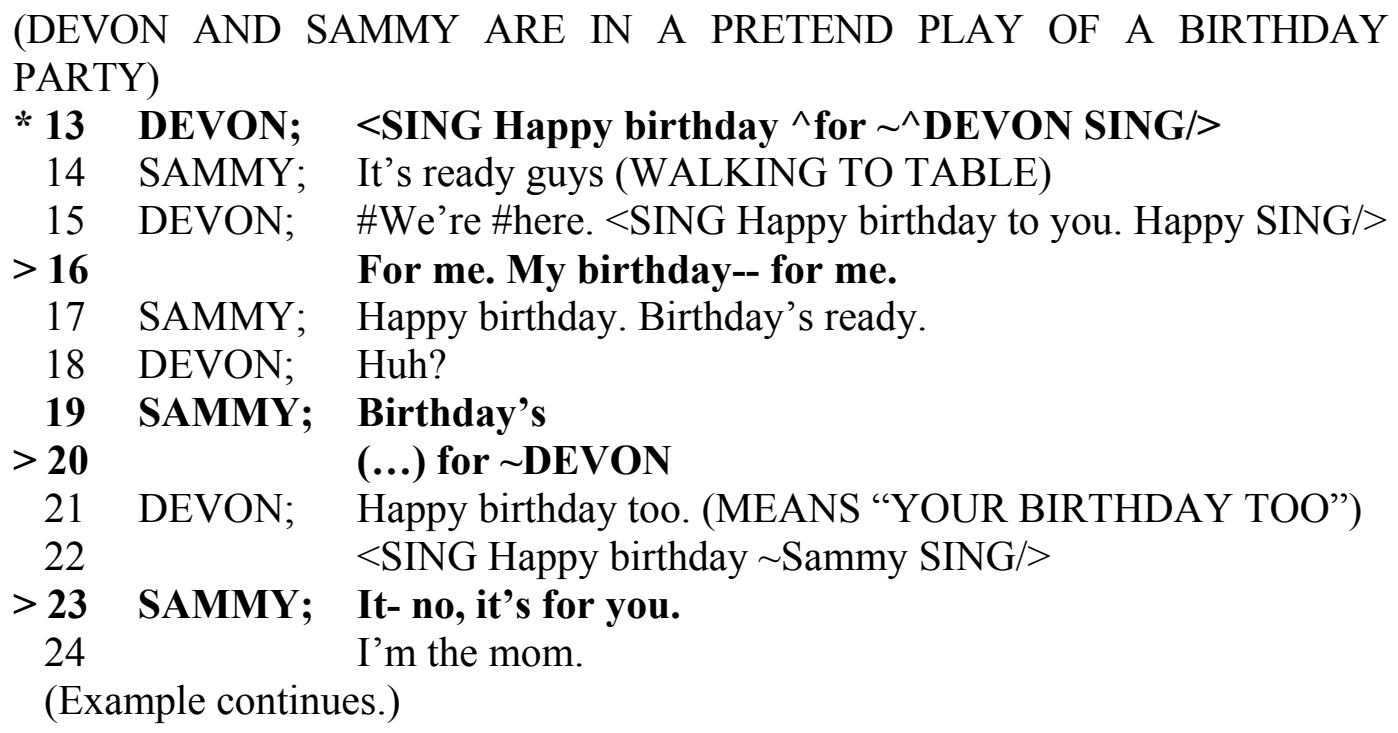




\section{Format Tying and Syntax in Toddlers' Peer Interactions}

In line 13, Devon sings the happy birthday song. He claims the birthday for himself by saying "For me. My birthday-- for me" in line 16. In line's 19-20, Sammy agrees with this statement and recycles Devon's "for me" construction by embedding it into a complete contracted copula construction, ("Birthday's ... for Devon"). In lines 21-22, there is conflict, in that Devon recycles the utterance that it's somebody's birthday by saying that it's for Sammy "Happy birthday Sammy." In line 23, she disagrees and recycles the same argument structure, again using the copula form, but puts Devon in the role of birthday person "it's for you." Moreover, she embeds this restructured statement in a negative construction, ("It- no, it's for you"). By embedding his statement in a negative construction, she turns around and refutes the statement he made in the previous turn. Across the two turns, the children practice turning negative and declarative forms of the same statement into one another. In the next line, she elaborates on her statement that it's for him by saying "I'm the mom." Being the mom positions her as an authority figure who can organize birthdays for others.

In example (3), we see that a preliminary argument structure "happy birthday, for Devon" evolves into a new argument structure with a contracted copula verb "Birthday's for Devon," and further into a negative contracted copula construction with a causal clause, "No, it's for you. I'm the mom." Hence, as the children attempt to top one anothers' statements and negate them, they evolve quite complex argument structures dialogically in the interaction.

\section{Discussion}

The main finding of this paper is that children seem to elaborate complex argument structures over sequences of conversational turns dialogically. In conflicts and discussions with their peers, through the practice of repeating and modifying the argument structures of one another's statements, children were provided an occasion to learn, practice, and appreciate the discursive underpinnings of the grammatical forms that they were contrasting across speaker turns. For instance, by juxtaposing two closely related forms "I go faster" vs. "I'm goin' faster" in an attempt to position themselves interactionally, they might begin to appreciate the functional context in which each of these forms might be appropriate.

These episodes of extended sequences of format tying provided an example of how discourse and grammar might be related in children's language acquisition (e.g. Budwig 1995, Clancy 1996, Cook-Gumperz and Kyratzis 2001, Ervin-Tripp 1993, Hopper 2001, Langacker 2001, Thompson and Hopper 2001). Usually the development of adverbs or the emergence of predicates is associated with cognitive development, such as mastery of relations of time, space, causality, purpose, obligation (Parisi and Antonucci 1974 as cited in Slobin 1979, Slobin 1979). However, as these examples suggested, in addition to cognitive factors, social and discursive factors were found to play a role and contribute to syntax acquisition and use. As found and suggested in previous studies (e.g. Du Bois 2001, Miller and Ervin 1964, Keenan 1977), participation and involvement in conversations through format tying and repetition provided very young children with a context 


\section{S. Bahar Köymen and Amy Kyratzis}

that facilitated their use and learning of quite complex grammatical constructions and argument structures.

Finally, this study highlights the scaffolding role of the interactant, similar to other studies on mother-child conversations (see also Bowerman 1976, Clancy 2009, Küntay and Slobin 1996, Ochs and Schieffelin 1984). However, this analysis departs from these studies in terms of how toddlers scaffold one another for syntax acquisition, thereby creating their own context for language learning.

\section{Appendix: Summary of Transcription Symbols}

\begin{tabular}{|c|c|c|}
\hline $\begin{array}{l}\text { MEANING } \\
\text { speaker attribution } \\
\text { pause, timed }\end{array}$ & $\begin{array}{l}\text { SYMBOL } \\
\text { JILL; } \\
(1.2)\end{array}$ & $\begin{array}{l}\text { COMMENTS } \\
\text { semicolon follows name in CAPS } \\
\text { pause duration in seconds, } \\
\text { tenths of seconds }\end{array}$ \\
\hline hold/micropause & .. & $<150$ milliseconds; brief silence \\
\hline pause, untimed & $\ldots$ & 0.2 seconds or more \\
\hline lag/prosodic lengthening & $:$ & colon marks slowing of local tempo \\
\hline overlap (first pair) & {$[\quad]$} & align left square brackets vertically \\
\hline overlap (2nd pair) & {$\left[\begin{array}{ll}2 & ]\end{array}\right.$} & $\begin{array}{l}\text { align left brackets, } \\
\text { with subscript numeral }\end{array}$ \\
\hline terminative & . & intonation morpheme signaling finality \\
\hline continuative & , & $\begin{array}{l}\text { intonation morpheme signaling } \\
\text { continuation }\end{array}$ \\
\hline truncated intonation unit & - & aborting projected intonation unit \\
\hline appeal & $?$ & combines with final/continuing: ?. ?, \\
\hline truncated/cut-off word & wor- & aborting projected word (en dash) \\
\hline laugh & & one per pulse or particle of laughter \\
\hline laughing word & @I@am & laugh symbol marks laughter during word \\
\hline unintelligible & \#\#\# & one symbol per syllable \\
\hline uncertain & \#I \#am & transcribed words are uncertain \\
\hline comment & $(($ WORDS $))$ & analyst comment on any topic \\
\hline pseudograph & $\sim$ Jill & name change to preserve anonymity \\
\hline
\end{tabular}

\section{References}

Bock, Kathryn J., and Helga Loebell. 1990. Framing sentences. Cognition 35:1-39. Bowerman, Melissa. 1976. Semantic factors in the acquisition of rules for word use and sentence construction. In D. M. Morehead, and A. E. Morehead, eds., Normal and deficient child language, 99-179. Oxford, England: University Park.

Budwig, Nancy. 1995. A developmental-functionalist approach to child language. Mahwah, NJ: Lawrence Erlbaum Associates. 
Clancy, Patricia. M. 1996. Referential strategies and the co-construction of argument structure in Korean acquisition. In B. Fox, ed., Studies in anaphora, 33-69. Amsterdam/Philedelphia: John Benjamins Publishing company.

Clancy, Patricia M. 2009. Dialogic priming and the acquisition of argument marking in Korean. In J. Guo, E. Lieven, N. Budwig, S. Ervin-Tripp, K. Nakamura and Ş. Özçalışkan, eds., Crosslinguistic approaches to the psychology of language: Research in the tradition of Dan Isaac Slobin, 105-117. New York, London: Psychology Press ,Taylor and Francis Group.

Cook-Gumperz, Jenny, and Amy Kyratzis. 2001. Pretend play: Trial ground for the simple present. In M. Putz, S. Niemeier, and R. Dirven, eds., Applied Cognitive Linguistics I: Theory and language acquisition, 41-62. Berlin-New York: Walter de Gruyter.

Corsaro, William. A., and Maynard, Douglas. 1996. Format tying in discussion and argumentation among Italian and American children. In D. Slobin, J. Gerhardt, A. Kyraztis, and J. Guo, eds., Social interaction, social context, and language: Essays in honor of Susan Ervin-Tripp, 157-174. Mahwah, NJ: Lawrence Erlbaum.

Du Bois, John W. 2001. Towards a dialogic syntax. Ms., University of California, Santa Barbara.

Du Bois, John W., Susanne Cumming, Stephan Schuetze-Coburn, and Danae Paolino. 1992. Discourse transcription. Santa Barbara Papers in Linguistics 4.

Ervin-Tripp, Susan M. 1993. Constructing syntax from discourse. In E.V. Clark, ed., Proceedings of the Twenty-fifth Annual Child Language Research Forum, 333-341. Stanford, CA: Center for the Study of Language and Information.

Goodwin, Marjorie H. 1990. He-said-she-said: Talk as social organization among black children. Bloomington, IN: Indiana University Press.

Goodwin, Marjorie H. 2006. The hidden life of girls: Games of stance, status, and exclusion. Oxford, UK: Blackwell Publishing.

Hopper, Paul J. 2001. Grammatical constructions and their discourse origins: Prototype or family resemblance?. In M. Putz, S. Niemeier, and R. Dirven, eds., Applied Cognitive Linguistics I: Theory and language acquisition, 109129. Berlin-New York: Walter de Gruyter.

Keenan, Elinor. 1977. Making it last: Repetition in children's discourse. In S. Ervin-Tripp and M. Kernan, eds., Child discourse, 125-139. New York: Academic Press.

Köymen, S. Bahar. 2008. Format tying: Relating to and varying the claims of others in the peer interactions of very young children. Unpublished Master's thesis, University of California, Santa Barbara.

Köymen, S. Bahar, and Amy Kyratzis. 2009. Dialogic syntax and format tying in rounds of claims in toddlers' peer interactions. Ms., University of California, Santa Barbara. 


\section{S. Bahar Köymen and Amy Kyratzis}

Küntay, Aylin, and Dan I. Slobin. 1996. Listening to a Turkish mother: Some puzzles for acquisition. In D. Slobin, J. Gerhardt, A. Kyraztis, and J. Guo, eds., Social interaction, social context, and language: Essays in honor of Susan Ervin-Tripp, 157-174. Mahwah, NJ: Lawrence Erlbaum.

Langacker, Ronald W. 2001. Cognitive Linguistics, language pedagogy, and the English present tense. In M. Putz, S. Niemeier, and R. Dirven, eds., Applied Cognitive Linguistics I: Theory and language acquisition, 3-39. Berlin-New York: Walter de Gruyter.

Miller, Wick and Susan M. Ervin. 1964. The development of grammar in child language. In U. Bellugi, and R. Brown, eds., The acquisition of language, Monographs of the Society for Research in Child Development 29(1): 9-34.

Ochs, Elinor, and Bambi B. Schiefflin. 1984. Language acquisition and socialization: Three developmental stories. In R. Schweder and R. LeVine, eds., Culture theory: Essays on mind, self, and emotion, 276-320. Cambridge: Cambridge University Press.

Parisi, Domenico, and Francesco Antinucci. 1974. Early language development: A second stage. In F. Bresson and J. Mehler, eds., Problèmes actuels en psycholinguistique, 129-143. Paris: Editions du Centre National de la Recherche Scientifique.

Slobin, Dan I. 1979. Psycholinguistics (2nd edition). Glenview, IL: Scott, Foresman.

Slobin, Dan I. 1985. Crosslinguistic evidence for the language-making capacity. In D. I. Slobin, ed., The crosslinguistic study of language acquisition, Vol. 2: Theoretical issues, 1157-1256. Hillsdale, N. J. Lawrence Erlbaum Associates.

Thompson, Sandra A., and Paul J. Hopper. 2001. Transitivity, clause structure, and argument structure: Evidence from conversation. In J. Bybee, and P. Hopper, eds., Frequency and the emergence of linguistic structure, 27-60. Amsterdam: John Benjamins.

Bahar Koymen and Amy Kyratzis

Gevirtz Graduate School of Education

University of California, Santa Barbara

Santa Barbara, CA 93106-9490

skoymen@education.ucsb.edu

kyratzis@education.ucsb.edu 